Article

\title{
Crystal Structure, Spectroscopy and Photocatalytic Properties of a Co(II) Complex Based on 5-(1,2,4-triazol-1-yl)pyridine-3-carboxylic Acid
}

\author{
Dawei Wang ${ }^{1, *}$, Ning Zhao ${ }^{2}$, Tao Wang ${ }^{3}{ }^{-}$, Changfu Zhuang ${ }^{1}$, Ying Wang ${ }^{1}$ and Bin Yang ${ }^{2, *}$ \\ 1 Key Laboratory of State Forestry and Grassland Administration on Highly-Efficient Utilization of Forestry \\ Biomass Resources in Southwest China, Southwest Forestry University, Kunming 650224, \\ China; cfzhuang163@163.com (C.Z.); yingwang_2009@163.com (Y.W.) \\ 2 Key Laboratory of Forest Disaster Warning and Control in Yunnan Province, Southwest Forestry University, \\ Kunming 650224, China; lijiangzhn@163.com \\ 3 Sichuan Vocational College of Chemical Technology, Luzhou 646099, China; wangtaochem@163.com \\ * Correspondence: wdw521@mail.ustc.edu.cn (D.W.); yangbin48053@yahoo.com.cn (B.Y.)
}

Received: 27 December 2019; Accepted: 4 February 2020; Published: 8 February 2020

\begin{abstract}
A novel cobalt(II) complex, namely $\left[\mathrm{Co}(\text { tpa })_{2}\left(\mathrm{H}_{2} \mathrm{O}\right)_{4}\right] \cdot 2 \mathrm{H}_{2} \mathrm{O}$ (1) $\quad(\mathrm{Htpa}=$ 5-(1,2,4-triazol-1-yl)pyridine-3-carboxylic acid) has been solvothermally synthesized and structurally characterized by single-crystal X-ray diffraction. Complex 1 was further characterized by elemental analysis, FTIR spectrum, electronic spectrum, X-ray powder diffraction and thermal gravimetric analysis. Structural analysis shows that complex 1 was stabilized via $\pi \cdots \pi$ stacking and hydrogen bonding interactions to give a 3D supramolecular framework. Hirshfeld surface analysis showed that $\mathrm{O} \cdots \mathrm{H}(29.5 \%), \mathrm{H} \cdots \mathrm{H}(23.8 \%), \mathrm{N} \cdots \mathrm{H}(21.5 \%)$ and $\pi \cdots \pi(8.6 \%)$ intermolecular contacts are the most important interactions in the crystal of $\mathbf{1}$. In addition, the synthesized Co(II) complex showed favorable photocatalytic activity for the degradation of methyl orange (MO) under UV light at room temperature. The degradation process of $\mathrm{MO}$ was in accordance with the first-order reaction kinetics, and the $t_{1 / 2}$ for the reaction is $27.3 \mathrm{~min}$, and the apparent rate constant is $k=2.54 \times 10^{-2} \mathrm{~min}^{-1}$.
\end{abstract}

Keywords: Co(II) complex; Hirshfeld surface analysis; photocatalysis; organic dye

\section{Introduction}

In the last few years, many metal-organic coordination compounds constructed by triazole ligands have been reported; some of them not only have charming molecular structures, but also promising physical properties [1-3]. In addition, the structure of coordination complexes will be influenced by the position of substituent groups in the ligands [4]. Recently, we have reported the structures, physical properties and intermolecular interaction analyses of several transition metal complexes derived from a series of rigid triazole-benzoic acid ligands [5,6].

Synthetic dyes used in the textile, leather and printing industry are difficult to degrade due to their stable molecular structure, and some of them are known to be toxic to the human body $[7,8]$. Common organic dyes, such as methylene blue (MB), congo red (CR), and methyl orange (MO) are widely used in textile, printing and packaging industries and have caused serious natural water pollution. Although different water treatment techniques have been developed to deal with dye pollution, photocatalytic degradation seemed to be the most promising method [8]. Therefore, the synthesis of efficient and environmentally friendly photocatalysts has attracted ever-increasing attention $[9,10]$. $\mathrm{TiO}_{2}{ }^{-}$and $\mathrm{ZnO}$-based semiconductor materials are the most widely used photocatalysts in recent decades [11,12]. However, the main drawback for these materials is the fast recombination of electrons and hole pairs generated by irradiation [13]. In recent years, a new 
emerging application of metal-organic complexes as photocatalysts for the degradation of organic dyes has been established [14,15]. For instance, cobalt complexes with different structures have been used to degrade organic dyes in water medium under UV or visible irradiation [16,17].

In continuation of our work, herein we describe the solvothermal synthesis, supramolecular structure, spectroscopic, thermal stability and photocatalytic activity of complex $\left[\mathrm{Co}(\mathrm{tpa})_{2}\left(\mathrm{H}_{2} \mathrm{O}\right)_{4}\right] \cdot 2 \mathrm{H}_{2} \mathrm{O}$, starting with a triazole ligand 5-(1,2,4-triazol-1-yl)pyridine-3-carboxylic acid (Htpa).

\section{Experimental}

\subsection{Materials and Methods}

All starting materials were purchased from commercial sources and used as received. All the organic solvents used in synthesis and analysis were analytical grade and purchased from commercial sources. Methyl orange (MO) was purchased from Sinopharm Chemical Reagent co., Ltd, China. C, $\mathrm{H}$ and $\mathrm{N}$ elemental analyses were tested on a Vario EL III organic elemental analyzer (Elementar, Langenselbold, Hesse, Germany). FTIR spectrum was obtained from $\mathrm{KBr}$ pellet on a Varian 640-IR spectrometer (Varian, Palo Alto, CA, USA) in the range of $400-4000 \mathrm{~cm}^{-1}$. Powder X-ray diffraction patterns were performed on a Rigaku TTR(III) diffractometer (Rigaku, Takatsuki, Osaka, Japan), $\mathrm{Cu} k \alpha$ radiation, $\lambda=1.5406 \AA$. Thermal analysis was performed on a Mettler Toledo TGA/DSC $1 / 1600$ (Mettler Toledo, Zurich, Switzerland) thermal analyzer from room temperature to $800{ }^{\circ} \mathrm{C}$ at a heating rate of $10^{\circ} \mathrm{C} \mathrm{min}^{-1}$. UV-Vis absorption spectra were measured on a Persee TU-1901 (Persee, Beijing, China) spectrometer.

\subsection{Synthesis of $\left[\mathrm{Co}(t p a)_{2}\left(\mathrm{H}_{2} \mathrm{O}\right)_{4}\right] \cdot 2 \mathrm{H}_{2} \mathrm{O}(1)$}

A mixture of $\mathrm{Co}\left(\mathrm{NO}_{3}\right)_{2} \cdot 6 \mathrm{H}_{2} \mathrm{O}(43.5 \mathrm{mg}, 0.15 \mathrm{mmol})$ and $\mathrm{Htpa}(19 \mathrm{mg}, 0.1 \mathrm{mmol})$ was dissolved in $6 \mathrm{~mL}$ deionized water, and the mixed solution was stirred for 10 minutes at room temperature. Then, the solution was sealed into a $25 \mathrm{~mL}$ Teflon-linear autoclave and heated at $150{ }^{\circ} \mathrm{C}$ for $48 \mathrm{~h}$. The reactant mixture was cooled to room temperature at $10{ }^{\circ} \mathrm{C}$ per hour. The solution was filtered and left undisturbed for 3 days, and red block crystals of complex 1 were obtained (yield: 55\%, based on Htpa ligand). Anal. Calcd. for $\mathrm{C}_{16} \mathrm{H}_{22} \mathrm{CoN}_{8} \mathrm{O}_{10}$ (\%): C 35.24, H 4.07, N 20.55; Found (\%): C 35.28, H 4.04, N 20.58 .

\subsection{X-ray Crystallography}

Single-crystal X-ray diffraction data for complex $\mathbf{1}$ was collected on a Bruker Smart Apex II CCD (Bruker, Munich, Bavaria, Germany) area detector using graphite monochromated Mo K $\alpha$ radiation $(\lambda=0.71073 \AA)$ at $293(2) \mathrm{K}$. The crystal structure was solved by the direct method procedure and refined by full-matrix least squares on $F^{2}$ with the use of the SHELXTL-2014 program [18]. The non-hydrogen atoms were refined anisotropically, and all hydrogen atoms were added theoretically. The crystallographic and refinement data of complex $\mathbf{1}$ are summarized in Table 1. CCDC deposition number 1947682 contains the supplementary crystallographic data for $\mathbf{1}$, which can be obtained free of charge via http://www.ccdc.cam.ac.uk/data_request/cif. 
Table 1. Crystal data and structure refinement for complex 1.

\begin{tabular}{cc}
\hline Complex 1 & \\
\hline Empirical formula & $\mathrm{C}_{16} \mathrm{H}_{22} \mathrm{CoN}_{8} \mathrm{O}_{10}$ \\
Formula weight & 545.34 \\
Temperature/K & $293(2)$ \\
Crystal system & triclinic \\
Space group & $P \overline{1}$ \\
$a / \AA$ & $6.8212(9)$ \\
$b / \AA$ & $9.0225(12)$ \\
$c / \AA$ & $10.1018(13)$ \\
$\alpha /{ }^{\circ}$ & $63.8650(10)$ \\
$\beta /{ }^{\circ}$ & $83.2140(10)$ \\
$\gamma /{ }^{\circ}$ & $76.5600(10)$ \\
Volume/ $\AA^{3}$ & $542.77(12)$ \\
$Z$ & 1 \\
$\rho_{\text {calcg/cm }}{ }^{3}$ & 1.668 \\
$F(000)$ & 281.0 \\
Crystal size/mm ${ }^{3}$ & $0.34 \times 0.23 \times 0.14$ \\
Radiation & MoK $\alpha(\lambda=0.71073)$ \\
Independent reflections & $1880, \mathrm{R}_{\text {int }}=0.0149$ \\
restraints/parameters & $0 / 165$ \\
Goodness-of-fit on $F^{2}$ & 1.087 \\
Final R indexes $[\mathrm{I}>=2 \sigma(\mathrm{I})]$ & $\mathrm{R}_{1}=0.0296, \mathrm{wR}=0.0781$ \\
Final $\mathrm{R}$ indexes [all data] & $\mathrm{R}_{1}=0.0311, \mathrm{wR} \mathrm{R}_{2}=0.0788$ \\
L. diff. peak/hole $/ \mathrm{e} \AA^{-3}$ & $0.36 /-0.34$ \\
\hline
\end{tabular}

\subsection{Hirshfeld Surface Analysis}

Hirshfeld surface analysis is a powerful technique used to understand the intermolecular interactions within crystals. Hirshfeld surface analyses for complex 1 were carried out using Crystal Explorer 3.1 computer programs, with bond lengths to hydrogen atoms set to standard values. For each point on the Hirshfeld surface, de is the distance from the point to the nearest nucleus external to the surface, and $d i$ is the distance to the nearest nucleus internal to the surface [19]. The normalized contact distance $\left(d_{\text {norm }}\right)$ is defined as $[19,20]$

$$
d_{\text {norm }}=\frac{\left(\mathrm{d}_{\mathrm{i}}-\mathrm{r}_{\mathrm{i}}^{\mathrm{vdw}}\right)}{\mathrm{r}_{\mathrm{i}}^{\mathrm{vdw}}}+\frac{\left(\mathrm{d}_{\mathrm{e}}-\mathrm{r}_{\mathrm{e}}^{\mathrm{vdw}}\right)}{\mathrm{re}_{\mathrm{e}}^{\mathrm{vdw}}}
$$

where $r_{i}{ }^{v d w}$ and $r_{e}{ }^{v d w}$ are the van der Waals radii of the atoms.

\subsection{Photocatalytic Experiments}

The photocatalytic behavior of $\left[\mathrm{Co}(\mathrm{tpa})_{2}\left(\mathrm{H}_{2} \mathrm{O}\right)_{4}\right] \cdot 2 \mathrm{H}_{2} \mathrm{O}(\mathbf{1})$ was tested for the degradation of methyl orange (MO) under UV irradiation at room temperature. A sample of $30 \mathrm{mg}$ powder crystals of complex 1 was immersed in $25 \mathrm{~mL}$ of MO solution (10 mg/L). The solution was kept in the dark for $1 \mathrm{~h}$ to ensure adsorption equilibrium. Then, the mixed solution was magnetically stirred and exposed to UV irradiation from a $400 \mathrm{~W}$, high-pressure mercury lamp. The mercury lamp was put in the chamber of the annular hollow quartz tube, then the circulating cold water flowed in the hollow quartz tube to ensure that the emitted light was cold. The distance between the lamp and the reaction solution was about $20 \mathrm{~cm}$. At given time intervals, about $3 \mathrm{~mL}$ of analytical samples were withdrawn and analyzed by the UV-Vis spectrometer. The control experiment was performed under the same conditions but without catalysts. 


\section{Results}

\subsection{Crystal Structure of $\left[\mathrm{Co}(t p a)_{2}\left(\mathrm{H}_{2} \mathrm{O}\right)_{4}\right] \cdot 2 \mathrm{H}_{2} \mathrm{O}$}

Single-crystal X-ray diffraction analysis reveals that complex $\mathbf{1}$ crystallizes in the triclinic space group $P \overline{1}$. The asymmetry unit of 1 contains one central $\mathrm{Co}(\mathrm{II})$ ion, one deprotonated tpa ${ }^{-}$ligand, two coordinated water molecules, and one lattice water molecule. As shown in Figure 1a, the Co(II) ion is six-coordinated with an $\mathrm{N}_{2} \mathrm{O}_{4}$ coordination environment. The Co-O distances are 2.0757(15) and 2.0933(16) $\AA$, and the Co-N bond length is 2.1821(17) $\AA$ (Table 2). The carboxylate group of tpa- ligand is deprotonated but not coordinated with the $\mathrm{Co}(\mathrm{II})$ ion.

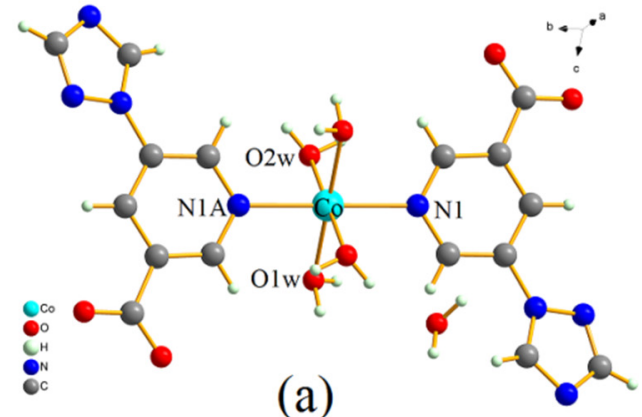

(a)

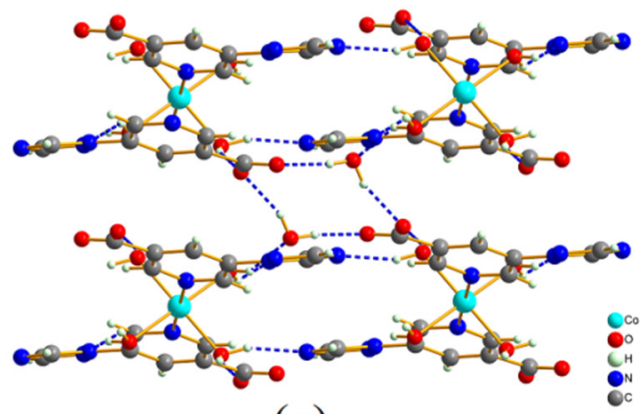

(c)

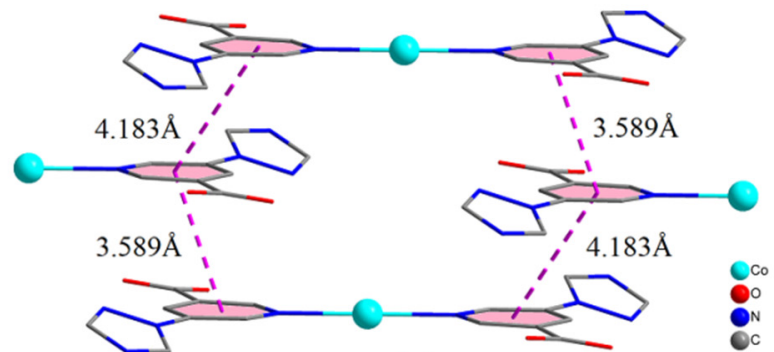

(b)

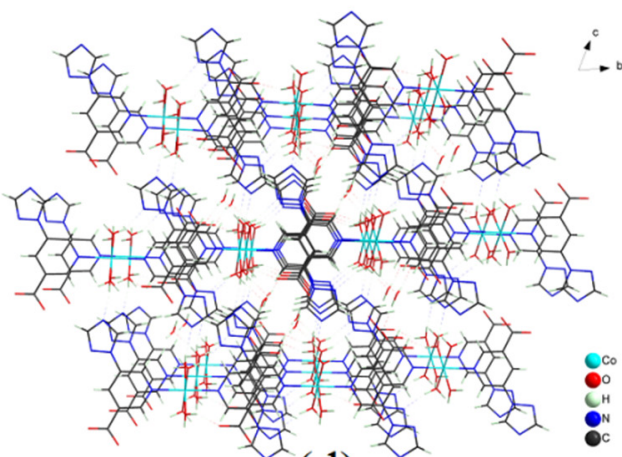

(d)

Figure 1. (a) Coordination environment of $\mathrm{Co}(\mathrm{II})$ atom in complex $1,(\mathbf{b}) \pi \cdots \pi$ stacking interactions between the adjacent benzene rings, (c) intermolecular $\mathrm{H}$ bonds for complex 1, (d) supramolecular framework of complex 1 formed by $\mathrm{H}$ bonds and $\pi \cdots \pi$ interactions (viewed along a axis).

Table 2. Selected bond lengths $(\AA)$ and angles $\left(^{\circ}\right)$ for complex 1 .

\begin{tabular}{cccc}
\hline \multicolumn{3}{c}{ Complex 1 } \\
\hline Co1-N1 & $2.1821(17)$ & O1W1-Co1-N11 & $89.62(6)$ \\
Co1-O1W & $2.0933(16)$ & O1W-Co1-N11 & $90.38(6)$ \\
Co1-O2W & $2.0757(15)$ & O2W-Co1-O1W & $89.98(7)$ \\
O1W-Co1-O1W1 & 180.0 & O2W1-Co1-O1W & $90.02(7)$ \\
\hline
\end{tabular}

${ }^{1}$ Symmetry code: $-x, 1-y,-z$.

As shown in Figure 1b, face-to-face $\pi \cdots \pi$ stacking interactions between the adjacent benzene rings can be obviously observed. The centroid to centroid distances between the two adjacent benzene rings are 3.589 and $4.183 \AA$, respectively. It can be concluded that the $\pi \cdots \pi$ interactions play an important role in stabilizing the crystal structure of $\mathbf{1}$.

Six groups of classical $\mathrm{O}-\mathrm{H} \cdots \mathrm{O}$ and $\mathrm{O}-\mathrm{H} \cdots \mathrm{N}$ hydrogen bonds are found in the packing structure of complex 1. The intermolecular hydrogen bonds are shown in Figure 1c, and the structural parameters of these hydrogen bonds are listed in Table 3. The coordinated water molecules act as $\mathrm{H}$ donors to form 
$\mathrm{O}-\mathrm{H} \cdots \mathrm{N}$ hydrogen bonds with triazole groups (O1W-H1WA $\cdots \mathrm{N} 3$ ), and form $\mathrm{O}-\mathrm{H} \cdots \mathrm{O}$ hydrogen bonds with carboxylate oxygen atoms (O1W-H1WB ‥O1). However, another coordinated water molecule acts as an $\mathrm{H}$ donor to form an $\mathrm{O}-\mathrm{H} \cdots \mathrm{N}$ hydrogen bond with $\mathrm{N} 2$ atom of triazole group (O2W-H2WA $\cdots \mathrm{N} 2)$, and form an $\mathrm{O}-\mathrm{H} \cdots \mathrm{O}$ hydrogen bond with lattice water $(\mathrm{O} 2 \mathrm{~W}-\mathrm{H} 2 \mathrm{WB} \cdots \mathrm{O} 3 \mathrm{~W})$. In addition, as the $\mathrm{H}$ donor, the lattice water also forms two $\mathrm{O}-\mathrm{H} \cdots \mathrm{O}$ hydrogen bonds with carboxylate oxygen atoms

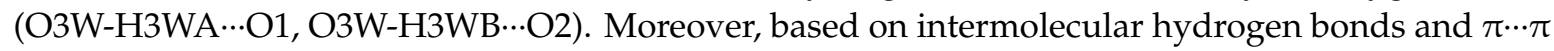
interactions, complex 1 further forms a stable 3D supramolecular framework (Figure 1d).

Table 3. Geometrical parameters for the hydrogen bonds in complex $\mathbf{1}$.

\begin{tabular}{|c|c|c|c|c|c|}
\hline D-H $\cdots A$ & $\mathrm{~d}(\mathrm{D}-\mathrm{H}) / \AA$ & $\mathrm{d}(\mathrm{H} \cdots \mathrm{A}) / \AA ̊$ & $d(D \cdots A) / \AA ̊$ & $<$ DHA $/^{\circ}$ & $\begin{array}{l}\text { Symmetry } \\
\text { Code }^{1}\end{array}$ \\
\hline O1W-H1WA ‥N3A & 0.881 & 1.970 & 2.818 & 161.31 & $-x,-y,-z+1$ \\
\hline O1W-H1WB ‥O1 & 0.880 & 1.953 & 2.778 & 155.63 & $-\mathrm{x},-\mathrm{y},-\mathrm{z}$ \\
\hline $\mathrm{O} 2 \mathrm{~W}-\mathrm{H} 2 \mathrm{WA} \cdots \mathrm{N} 2 \mathrm{~A}$ & 0.858 & 2.200 & 2.892 & 137.61 & $-x,-y,-z$ \\
\hline $\mathrm{O} 2 \mathrm{~W}-\mathrm{H} 2 \mathrm{WB} \cdots \mathrm{O} 3 \mathrm{~W}$ & 0.858 & 1.905 & 2.651 & 144.42 & $-x,-y+1,-z$ \\
\hline O3W-H3WA $\cdots \mathrm{O} 1$ & 0.850 & 1.914 & 2.733 & 161.22 & $-x+1,-y,-z$ \\
\hline O3W-H3WB $\cdots \mathrm{O} 2$ & 0.850 & 1.846 & 2.691 & 172.85 & $x, y, z+1$ \\
\hline
\end{tabular}

${ }^{1}$ The symmetry codes were obtained based on A atoms in the packing structure of complex 1 (D donor atom, A acceptor atom).

\subsection{Hirshfeld Surface of $\left[\mathrm{Co}(\mathrm{tpa})_{2}\left(\mathrm{H}_{2} \mathrm{O}\right)_{4}\right] \cdot 2 \mathrm{H}_{2} \mathrm{O}(\mathbf{1})$}

The 3D Hirshfeld surfaces of complex 1 are illustrated in Figure 2, which maps $\mathrm{d}_{\text {norm, }}$, shape index and curvedness [21]. The $\mathrm{d}_{\text {norm }}$ Hirshfeld surfaces displayed using a red-white-blue color scheme, where the red spots indicate the close contact interactions, white color indicate contacts around the van der Waals radius distance, and blue color is for longer contacts [19]. As shown in Figure 2a, the deep red spots on the $\mathrm{d}_{\text {norm }}$ Hirshfeld surface indicate the close contact interactions, which are mainly responsible for the significant intermolecular $\mathrm{O}-\mathrm{H} \cdots \mathrm{O}$ and $\mathrm{O}-\mathrm{H} \cdots \mathrm{N}$ hydrogen bonds, created by carboxyl groups (spot A), coordinated water (spot B), triazole nitrogen atoms (spot C) and lattice water (spot D). For the shape index plot (Figure 2b), the orange-red areas represent concave regions, indicating that there are hydrogen bonding or $\pi \cdots \pi$ stacking interactions in these areas. For the curvedness plot (Figure 2c), the flat areas of the surface indicate interactions between neighboring molecules. In addition, the flat regions above the benzene and triazole rings refer to the strong $\pi \cdots \pi$ stacking interactions between the aromatic rings of adjacent molecules.

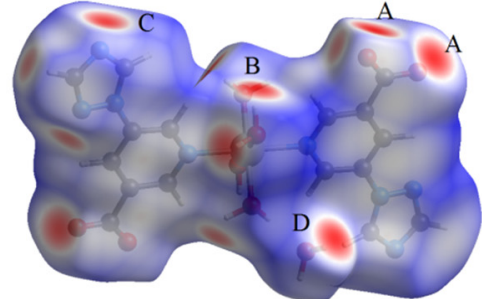

(a)

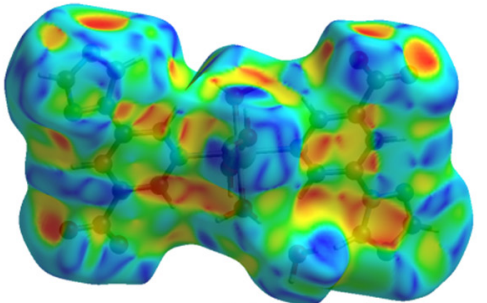

(b)

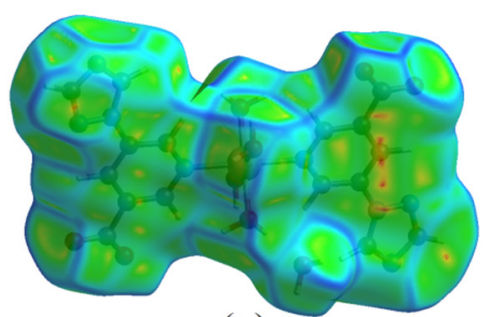

(c)

Figure 2. Hirshfeld surfaces of complex 1 mapped with (a) $d_{\text {norm }}$ (b) shape index and (c) curvedness.

As shown in Figure 3, a 2D fingerprint plot was performed to identify important intermolecular interactions, which was further decomposed to highlight particular atom pairs' close contacts. It is found that there are five kinds of intermolecular interactions, including $\mathrm{O} \cdots \mathrm{H}, \mathrm{N} \cdots \mathrm{H}, \mathrm{H} \cdots \mathrm{H}, \mathrm{C} \cdots \mathrm{H}$ and $\mathrm{C} \cdots \mathrm{C}(\pi \cdots \pi)$ interactions. The $\mathrm{O} \cdots \mathrm{H} / \mathrm{H} \cdots \mathrm{O}$ intermolecular interactions comprise $29.5 \%$ of the total Hirshfed surface, which appear as two distinct spikes in the $2 \mathrm{D}$ fingerprint plot (Figure $3 \mathrm{~b}$ ). It can be inferred from the strongest spike that the $\mathrm{O} \cdots \mathrm{H}$ interaction is the shortest contact, with a minimum value of $(\mathrm{de}+\mathrm{di})$ around $1.7 \AA$ [22]. The $\mathrm{N} \cdots \mathrm{H} / \mathrm{H} \cdots \mathrm{N}$ interactions also appear as two sharp spikes, 
which comprise $21.5 \%$ of the total Hirshfed surface (Figure 3c). Apart from those mentioned above, the $\mathrm{H} \cdots \mathrm{H}$ interactions also have a large contribution to the total Hirshfed surface, comprising $23.8 \%$. It is interesting that $\mathrm{C} \cdots \mathrm{C}$ interactions are found in the $2 \mathrm{D}$ fingerprint plot, which comprised $8.6 \%$ of the total Hirshfed surface (Figure 3f). The C...C interactions are mainly caused by the strong $\pi \cdots \pi$ stacking interactions between adjacent aromatic rings. From the 2D fingerprint plots, we can also find that the $\pi \cdots \pi$ stacking interactions have much longer contact distances when compared with hydrogen bonding interactions. The $\mathrm{H}$ bonding and $\pi \cdots \pi$ stacking information conveyed by Hirshfeld surface analyses are consistent with the crystal structure analyses.

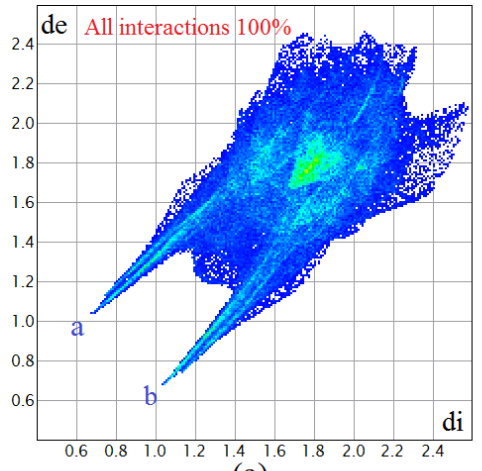

(a)

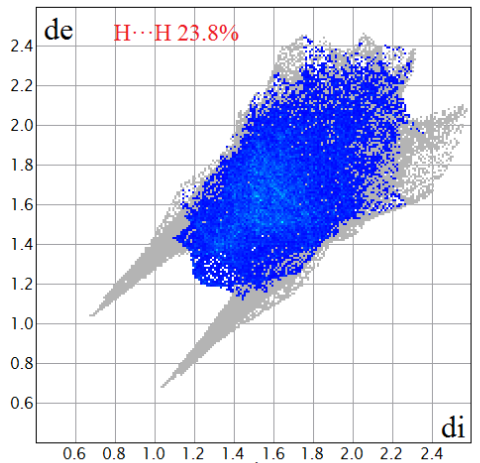

(d)

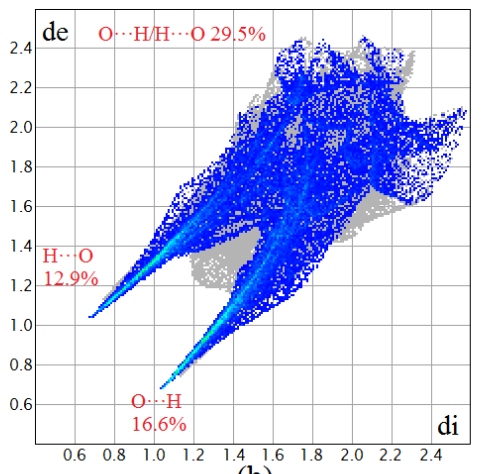

(b)

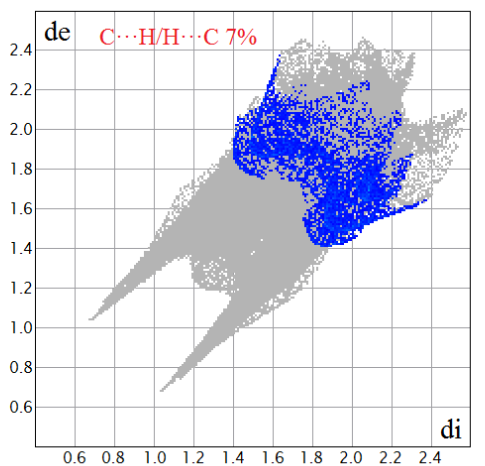

(e)

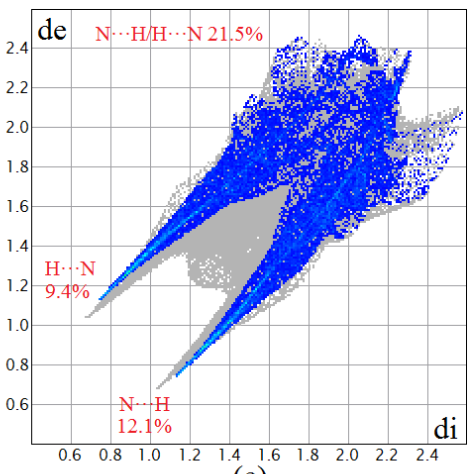

(c)

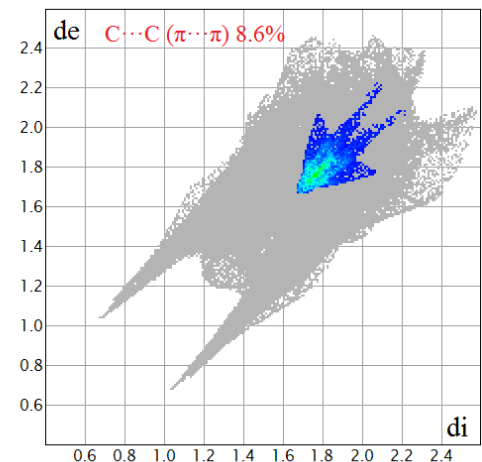

(f)

Figure 3. Fingerprint plots of complex 1: full (a) and resolved into $\mathrm{O} \cdots \mathrm{H}(\mathbf{b}), \mathrm{N} \cdots \mathrm{H}(\mathbf{c}), \mathrm{H} \cdots \mathrm{H}(\mathbf{d}), \mathrm{C} \cdots \mathrm{H}$ (e) and C...C (f) contacts showing the percentages of contacts contributed to the total Hirshfeld surface area of molecules.

\subsection{XRD and Thermal Stability}

As shown in Supplementary Materials Figure S1, the experimental XRD pattern agrees well with the simulated pattern generated on the basis of the single-crystal analysis for complex 1, which suggests good phase purity and homogeneity of the synthesized sample. The thermal behavior of complex 1 was studied by gravimetric analysis (TGA). In the TGA curve (Figure S2), the first step takes place in the range of $60-147^{\circ} \mathrm{C}$ with a weight loss of $13.0 \%$, which can be attributed to the gradual release of four coordinated $\mathrm{H}_{2} \mathrm{O}$ (calcd. 13.2\%). After that, the skeleton of the complex begins to decompose and a significant weight loss of $22.1 \%$ is observed in the range of $264-425{ }^{\circ} \mathrm{C}$, which could be assigned to the decomposition of the triazole group (calcd. 24.9\%). Keeping the heat at $900{ }^{\circ} \mathrm{C}$, consecutive decompositions suggest the total destruction of the framework, and at last a residue of CoO remained (obsd. 16.6\%, calcd. 13.7\%).

\subsection{FT-IR and UV-Vis Absorption Spectra}

In the FT-IR spectrum of complex 1 (Figure S3), the broad absorption band at about 3300-3500 $\mathrm{cm}^{-1}$ can be assigned to the $-\mathrm{OH}$ stretching vibrations of water, including water ligands, lattice water and 
absorbed water molecules. The bands at 1582 and $1385 \mathrm{~cm}^{-1}$ are attributed to the stretching vibrations of $\mathrm{C}=\mathrm{C}$ and $\mathrm{C}=\mathrm{N}$ bonds from benzene and triazole rings [23]. As shown in Figure S4, the UV-Vis absorption spectrum of complex $\mathbf{1}$ was measured in methanol solution at room temperature (concentrations ca. $10^{-5} \mathrm{M}$ ). Complex 1 has three absorption bands with different intensities, where the two strong absorption bands at 212 and $239 \mathrm{~nm}$ can be attributed to the $\pi \rightarrow \pi^{*}$ transition absorption of aromatic rings $(C=C)$, while the weak band at $276 \mathrm{~nm}$ can be assigned to the $\mathrm{n} \rightarrow \pi^{*}$ transition of the triazole group $(\mathrm{C}=\mathrm{N})[24]$.

\subsection{Photocatalytic Activity}

The removal of toxic organic dyes from contaminated water is very important from the perspective of environmental protection. The photocatalytic degradation of methyl orange (MO) in aqueous solution by complex 1 under UV irradiation is shown in Figure 4a. It can be found from the absorption spectra that the absorption intensity of MO solution decreased gradually with the reaction time under the catalysis of complex 1, and the MO is almost completely degraded after 90 min of light irradiation. Degradation efficiencies (D) for $\mathrm{MO}$ dye was calculated as $\mathrm{D}=\left(\mathrm{A}_{0}-\mathrm{A}_{t}\right) / \mathrm{A}_{0} \times 100 \%$ [25], where $A_{0}$ is the initial absorbance of MO solution at $\lambda_{\max }=464 \mathrm{~nm}$, and $\mathrm{A}_{\mathrm{t}}$ is the absorbance obtained at $t \mathrm{~min}$. As shown in Figure $4 b$, the degradation efficiency of $\mathrm{MO}$ is about $51.9 \%$ after reacting for $30 \mathrm{~min}$, and is up to $89.2 \%$ after irradiating for $90 \mathrm{~min}$, which indicates the high catalytic efficiency of complex 1 . In contrast, the degradation efficiency of $\mathrm{MO}$ is only $14.9 \%$ after irradiating for $90 \mathrm{~min}$ in the absence of complex 1. In addition, we measured the XRD pattern of $\mathbf{1}$ after the photocatalytic experiment, which was identical to the corresponding one of the original compound (Figure S1), indicating that the crystal structure of complex 1 was stable after photocatalytic reactions. The catalyst was reused three times to study its reusable performance, as shown in Figure 5a. The catalyst retained favorable photocatalytic efficiencies after reused for two cycles, with the degradation efficiency of MO decreased from $89.3 \%$ to $80.5 \%$. However, after being reused for three cycles, the degradation efficiency of $\mathrm{MO}$ decreased to $65.2 \%$.
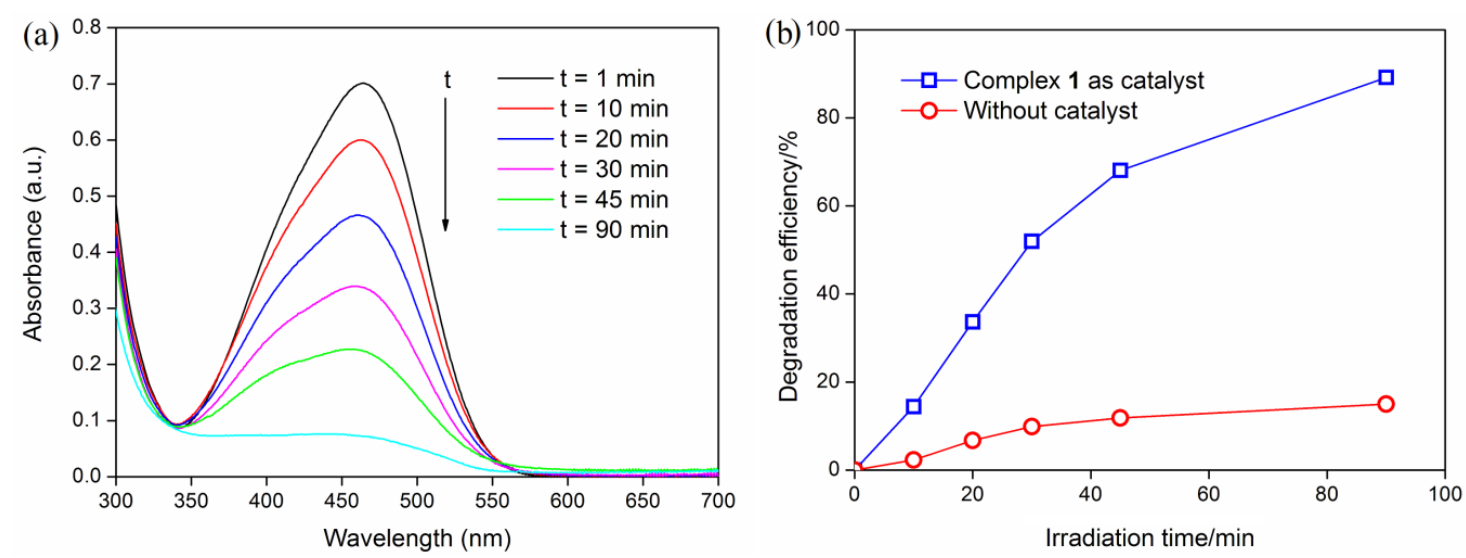

Figure 4. (a) The UV-Vis absorption spectra of methyl orange (MO) solution during the decomposition reaction under UV irradiation; (b) Degradation efficiencies of MO under UV light. 

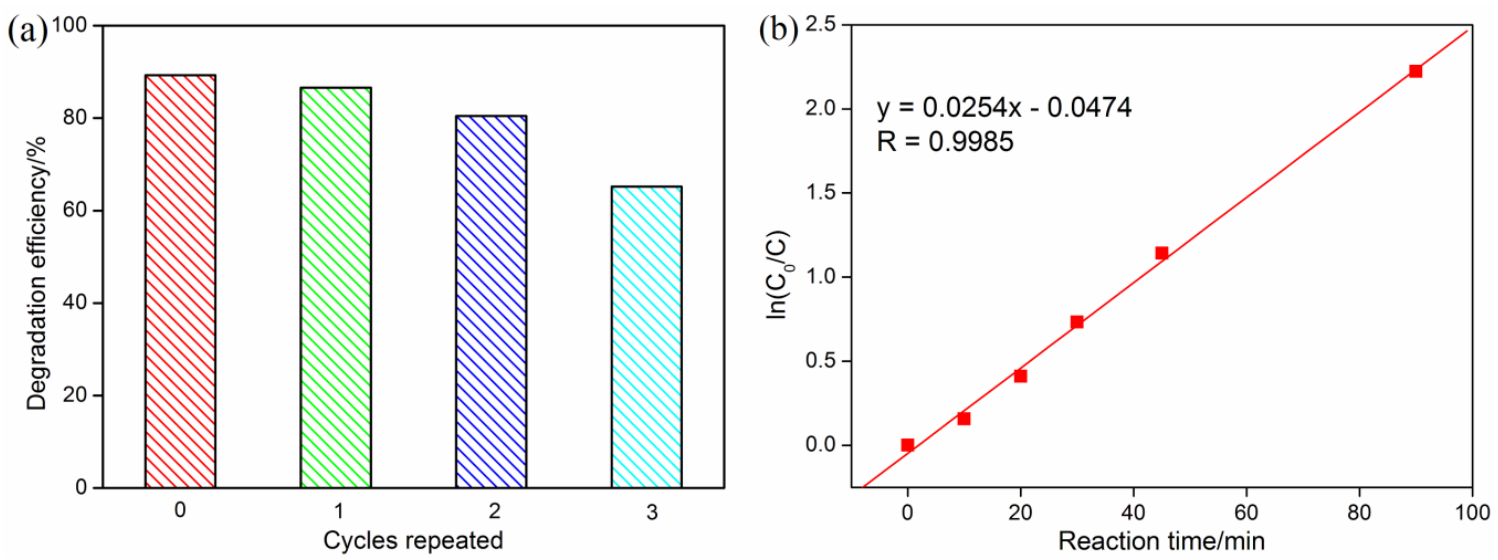

Figure 5. (a) Reusable degradation activity of complex 1 (irradiation time $90 \mathrm{~min}$, the catalyst was centrifuged, filtered and dried for the next experiment); (b) pseudo-first-order kinetics for the degradation of MO under UV light.

Reaction kinetics studies have shown that the degradation process of $\mathrm{MO}$ was in accordance with the pseudo-first-order model, $\ln \left(C_{0} / C_{t}\right)=k \cdot t$, where $C_{0}$ and $C_{t}$ were the concentrations of $\mathrm{MO}$ solution at irradiation time $t_{0}$ and $t$ [26]. As shown in Figure $5 b$, the $\ln \left(C_{0} / C_{t}\right)$ versus $t$ showed a linear relationship, with the correlation coefficient $R=0.9985(p<0.0001)$, and the apparent rate constant $k=$ $2.54 \times 10^{-2} \mathrm{~min}^{-1}$. As an important parameter of the pseudo-first-order reaction, the half-life time $t_{1 / 2}$ (calculated as $t_{1 / 2}=\ln 2 / k$ ) means the time at which $C=0.5 C_{0}[27,28]$. The $t_{1 / 2}$ for the photocatalytic reaction of $\mathrm{MO}$ is $27.3 \mathrm{~min}$, implying that complex $\mathbf{1}$ is an effective photocatalyst.

The mechanism of photocatalytic degradation of organic dyes by metal-organic complexes has been described in detail in much of the literature, which proved that these reactions were mainly based on the advanced oxidation of hydroxyl radicals $(\cdot \mathrm{OH})$ [29]. In aqueous solution, under the excitation of UV light, $\mathrm{N}-\mathrm{Co}$ charge transfer occurs between the ligands and the metal center of complex 1, promoting electrons from the highest occupied molecular orbital (HOMO) to the lowest unoccupied molecular orbital (LUMO). Therefore, the highest occupied molecular orbital strongly needs an electron to return to its stable state. The electrons are captured from aqueous solution to generate $\cdot \mathrm{OH}$ radicals. At the same time, the electrons excited to the LUMO are captured by water to generate $\cdot \mathrm{OH}$ radicals $[14,29,30]$. Finally, the oxidizing $\cdot \mathrm{OH}$ radicals decomposed $\mathrm{MO}$ dye to complete the photocatalytic process. Wang and co-workers studied the photocatalytic activity of six different complexes [30]. They observed that the Co(II) complexes show much better photocatalytic activity than that of the $\mathrm{Cu}(\mathrm{II}), \mathrm{Ni}(\mathrm{II}), \mathrm{Zn}$ (II) and $\mathrm{Cd}(\mathrm{II})$ complexes in the degradation of different types of organic dyes. They also pointed out that the different structures and central metal ions of complexes might affect the photocatalytic activity, but the reasons are still unclear. For the synthesized Co(II) complex 1, the $\mathrm{N}$ atom of pyridine ring on the ligand coordinate with the cobalt atoms. The pyridine ring is a stable aromatic structure; when the Co(II) complex is excited by UV light, the charges can be distributed over the entire pyridine ring, which promotes the separation of photogenerated electrons and positive charges, making the excited state more stable [30,31]. Besides, in aqueous solution, the presence of four coordination water molecules may contribute to the production of hydroxyl radicals (Figure S5). Moreover, Lin et al. point out that the charge-carrier mobility of materials is affected by $\pi$ conjugation and $\pi \cdots \pi$ stacking [32]. We can infer from the single-crystal structure of complex 1 that the $\pi \cdots \pi$ stacking structure makes the photogenerated electrons more stable, which will facilitate the transfer of photogenerated electrons to water to produce hydroxyl radicals.

\section{Conclusions}

In summary, a novel $\mathrm{Co}(\mathrm{II})$ complex $\left[\mathrm{Co}(\mathrm{tpa})_{2}\left(\mathrm{H}_{2} \mathrm{O}\right)_{4}\right] \cdot 2 \mathrm{H}_{2} \mathrm{O}(\mathbf{1})$ has been synthesized using multifunctional triazole derivative as an organic ligand. Hirshfeld surface analysis was used to study 
the intermolecular interactions, which revealed that the $\mathrm{O} \cdots \mathrm{H}, \mathrm{H} \cdots \mathrm{H}, \mathrm{N} \cdots \mathrm{H}$ and $\pi \cdots \pi$ contacts were the most significant interactions in the crystal of complex 1 . The hydrogen bonding and $\pi \cdots \pi$ stacking information conveyed by Hirshfeld surface analyses were consistent with the crystal structure analyses. Photocatalytic studies revealed that complex 1 could effectively catalyze the degradation of MO dye under UV irradiation, and the degradation process was in accordance with the pseudo-first-order kinetics model.

Supplementary Materials: The following are available online at http://www.mdpi.com/2073-4352/10/2/98/s1, Figure S1: XRD patterns of complex 1, Figure S2: TGA curve of complex 1, Figure S3: FT-IR spectrum of complex 1, Figure S4: UV absorption spectrum of complex 1 in methanol solution at room temperature, Figure S5: Possible photocatalytic mechanisms showing the two excited states of Co(II) catalyst under UV excitation.

Author Contributions: D.W. and B.Y. conceived and designed the experiments; T.W. and Y.W. performed X-ray structure determination and analyzed the results; D.W., N.Z. and C.Z. carried out the synthetic and photocatalytic experiments. All authors took part in writing and discussion processes. All authors have read and agreed to the published version of the manuscript.

Funding: This work is supported by the National Natural Science Foundation of China (No. 31760190), the Project on applied basic research in Yunnan (No. 2016FB052), and the Research Launch Fund of Southwest Forestry University (No. 111921).

Acknowledgments: The authors would like to thank the forestry engineering postdoctoral station of Southwest Forestry University.

Conflicts of Interest: The authors declare no conflict of interest.

\section{References}

1. Wang, Y.L.; Fu, J.H.; Wei, J.J.; Xu, X.; Li, X.F.; Liu, Q.Y. Noncentrosymmetric organic solid and its zinc coordination polymer with diamonded network prepared from an ionothermal reaction: Syntheses, crystal structures, and second-order nonlinear optics properties. Cryst. Growth Des. 2012, 12, 4663-4668. [CrossRef]

2. Luo, Y.S.; Chen, J.L.; Zeng, X.H.; Qiu, L.; He, L.H.; Liu, S.J.; Wen, H.R. A highly stable and luminescent mononuclear $\mathrm{Cu}(\mathrm{I})$ bis-\{5-tert-butyl-3-(6-methyl-2-pyridyl)-1H-1,2,4-triazole\} complex. Chin. Chem. Lett. 2017, 28, 1027-1030. [CrossRef]

3. Yan, Y.T.; Zhang, S.S.; Yang, G.P.; Zhang, W.Y.; Zhang, F.; Cao, F.; Yang, R.F.; Wang, Y.Y. The influence of coordination modes and active sites of a 5-(triazol-1-yl) nicotinic ligand on the assembly of diverse MOFs. Dalton Trans. 2017, 46, 9784-9793. [CrossRef] [PubMed]

4. Wu, J.F.; Guo, M.; Li, X.L.; Zhao, L.; Sun, Q.F.; Layfield, R.A.; Tang, J.K. From double-shelled grids to supramolecular frameworks. Chem. Commun. 2018, 54, 12097-12100. [CrossRef] [PubMed]

5. Wang, D.W.; Wang, T.; Yan, T.; Du, L.; Zhao, Q.H. Crystal structures and spectroscopic characterizations of two Cd(II) complexes based on [1,2,4]-triazole derivatives. Chin. J. Inorg. Chem. 2017, 33, 1443-1449.

6. Wang, D.W.; Wang, T.; Yan, T.; Du, L.; Zhao, Q.H. Crystal structure, spectroscopic and thermal properties of copper(II) and manganese(II) coordination polymers based on triazole-benzoic acid ligands. Transit. Met. Chem. 2018, 43, 1-8. [CrossRef]

7. Harandi, Z.J.; Nasab, S.G.; Teimouri, A. Synthesis and characterisation of magnetic activated carbon/diopside nanocomposite for removal of reactive dyes from aqueous solutions: Experimental design and optimization. Int. J. Environ. Anal. Chem. 2019. [CrossRef]

8. Cui, J.W.; Hou, S.X.; Li, Y.H.; Cui, G.H. A multifunctional Ni(II) coordination polymer: Synthesis, crystal structure and applications as a luminescent sensor, electrochemical probe, and photocatalyst. Dalton Trans. 2017, 46, 16911-16924. [CrossRef]

9. Li, Z.R.; Mei, J.X.; Bai, L. Synthesis of $\mathrm{C}_{3} \mathrm{~N}_{4}$-decorated $\mathrm{ZnO}$ and $\mathrm{Ag} / \mathrm{ZnO}$ nanoparticles via calcination of ZIF-8 and melamine for photocatalytic removal of methyl orange. Chem. Pap. 2019, 73, 883-889. [CrossRef]

10. Li, Z.C.; Ma, J.J.; Zhang, B.; Song, C.X.; Wang, D.B. Crystal phase- and morphology-controlled synthesis of $\mathrm{MoO}_{3}$ materials. CrystEngComm 2017, 19, 1479-1485. [CrossRef]

11. Foura, G.; Chouchou, N.; Soualah, A.; Kouachi, K.; Guidotti, M.; Robert, D. Fe-doped $\mathrm{TiO}_{2}$ supported on HY zeolite for solar photocatalytic treatment of dye pollutants. Catalysts 2017, 7, 344. [CrossRef]

12. Lee, K.M.; Lai, C.W.; Ngai, K.S.; Juan, J.C. Recent developments of zinc oxide based photocatalyst in water treatment technology: A review. Water Res. 2016, 88, 428-448. [CrossRef] 
13. Xu, K.C.; Wu, J.G.; Tan, C.F.; Ho, G.W.; Wei, A.; Hong, M.H. Ag-CuO-ZnO metal-semiconductor multiconcentric nanotubes for achieving superior and perdurable photodegradation. Nanoscale 2017, 9, 11574-11583. [CrossRef]

14. Wu, Y.; He, J.; Wang, S.Q.; Zou, L.K.; Wu, X.R. Syntheses, crystal structure, and photocatalytic property of two new complexes of an unsymmetrical Schiff base ligand. Inorg. Chim. Acta 2017, 458, 218-223. [CrossRef]

15. Qin, L.; Xiao, S.L.; Ma, P.J.; Cui, G.H. Synthesis, crystal structures and catalytic properties of Ag(I) and Co(II) 1D coordination polymers constructed from bis(benzimidazolyl)butane. Transit. Met. Chem. 2013, 38, 627-633. [CrossRef]

16. Li, J.X.; Li, Y.F.; Liu, L.W.; Cui, G.H. Luminescence, electrochemical and photocatalytic properties of sub-micron nickel(II) and cobalt(II) coordination polymers synthesized by sonochemical process. Ultrason. Sonochem. 2018, 41, 196-205. [CrossRef]

17. Wang, D.W.; Yang, S.L.; Zhuang, C.F.; Wang, Y.; Shi, Z.J. Crystal structure, Hirshfeld surface analysis and photocatalytic activities of a cobalt(III) complex based on acid and alkaline mixed ligands. Transit. Met. Chem. 2019, 44, 455-461. [CrossRef]

18. Sheldrick, G.M. Crystal structure refinement with SHELXL. Acta Cryst. 2015, C71, 3-8.

19. Zhang, C.G.; Li, Y.; Luo, Y.H.; Sun, B.W. Two novel salts of tris(hydroxymethyl)aminomethane (THAM): Synthesis, crystal structure, thermal and Hirshfeld surfaces analysis. J. Chem. Crystallogr. 2013, 43, 576-584. [CrossRef]

20. Roy, S.; Harms, K.; Chattopadhyay, S. Synthesis, characterization and photocatalytic activity of a dinuclear thiocyanate bridged cadmium(II) Schiff base complex. Polyhedron 2017, 127, 471-477. [CrossRef]

21. Luo, Y.H.; Liu, Q.L.; Yang, L.J.; Wang, W.; Ling, Y.; Sun, B.W. Quantitative comparisons between $\alpha, \beta, \gamma$ and $\delta$ pyrazinamide (PZA) polymorphs. Res. Chem. Intermed. 2015, 41, 7059-7072. [CrossRef]

22. Seth, S.K.; Maity, G.C.; Kar, T. Structural elucidation, Hirshfeld surface analysis and quantum mechanical study of para-nitro benzylidene methyl arjunolate. J. Mol. Struct. 2011, 1000, 120-126. [CrossRef]

23. Fang, D.L.; Mo, S.Y.; Wu, K.F.; Huang, Z.J. Synthesis, crystal structures, and properties of three coordination polymers of 5-(1H-imidazol-1-yl) isophthalic acid. Transit. Met. Chem. 2017, 42, 273-283. [CrossRef]

24. Wang, D.W.; Wang, T.; Du, L.; Zhou, J.; Yan, T.; Zhao, Q.H. Four supramolecular transition metal(II) complexes based on triazole-benzoic acid derivatives: Crystal structure, Hirshfeld surface analysis, spectroscopic and thermal properties. Struct. Chem. 2018, 29, 1013-1023. [CrossRef]

25. Azam, M.; Al-Resayes, S.; Wabaidur, S.M.; Trzesowska-Kruszynska, A.; Kruszynski, R.; Mohapatra, R.K.; Siddiqui, M.R. Cd(II) complex constructed from dipyridyl imine ligand: Design, synthesis and exploration of its photocatalytic degradation properties. Inorg. Chim. Acta 2018, 471, 698-704. [CrossRef]

26. Liu, W.; Wang, M.L.; Xu, C.X.; Chen, S.F.; Fu, X.L. One-pot synthesis of $\mathrm{ZnO}_{2} / \mathrm{ZnO}$ composite with enhanced photocatalytic performance for organic dye removal. J. Nanosci. Nanotechnol. 2013, 13, 657-665. [CrossRef]

27. Mansour, A.M.; Bakry, E.M.; Abdel-Ghani, N.T. Photocatalytic degradation of methylene blue with copper(II) oxide synthesized by thermal decomposition of flubendazole complexes. J. Photoch. Photobiol. A 2016, 327, 21-24. [CrossRef]

28. Neto, J.O.M.; Bellato, C.R.; Souza, C.H.F.; Silva, R.C.; Rocha, P.A. Synthesis, characterization and enhanced photocatalytic activity of iron oxide/carbon nanotube/Ag-doped $\mathrm{TiO}_{2}$ nanocomposites. J. Braz. Chem. Soc. 2017, 28, 2301-2312.

29. Zhang, X.T.; Fan, L.M.; Fan, W.L.; Li, B.; Liu, G.Z.; Liu, X.Z.; Zhao, X. Structural diversity, luminescence and photocatalytic properties of six coordination polymers based on designed bifunctional 2-(imidazol-1-yl)terephthalic acid. CrystEngComm 2016, 18, 6914-6925. [CrossRef]

30. Wang, X.L.; Luan, J.; Lin, H.Y.; Lu, Q.L.; Le, M.; Liu, G.C.; Shao, J.Y. Metal(II)-organic coordination polymers modulated by two isomeric semirigid bis-pyridyl-bis-amide ligands: Structures, fluorescent sensing behavior, and selective photocatalysis. ChemPlusChem 2014, 79, 1691-1702. [CrossRef] 
31. Korala, L.; Germain, J.R.; Chen, E.; Pala, I.R.; Li, D.; Brock, S.L. CdS aerogels as efficient photocatalysts for degradation of organic dyes under visible light irradiation. Inorg. Chem. Front. 2017, 4, 1451-1457. [CrossRef]

32. Lin, S.; Diercks, C.S.; Zhang, Y.B.; Kornienko, N.; Nichols, E.M.; Zhao, Y.; Paris, A.R.; Kim, D.; Yang, P.D.; Yaghi, O.M.; et al. Covalent organic frameworks comprising cobalt porphyrins for catalytic $\mathrm{CO}_{2}$ reduction in water. Science 2015, 349, 1208-1212. [CrossRef] 